\title{
Pengaruh Oleamida Terhadap Karakteristik Pematangan Karet Alam Terisi Silika
}

\author{
Influence of Oleamide on the Curing Characteristic of Silica-Filled Natural Rubber
}

\author{
Indra Surya*, Philbert \\ Departemen Teknik Kimia, Fakultas Teknik, Universitas Sumatera Utara \\ Jl. Almamater Kampus USU Medan 20155, Indonesia \\ *Email: isurya@usu.ac.id
}

\begin{abstract}
Abstrak
Penelitian ini bertujuan sebagai suatu studi kelayakan penggunaan oleamida sebagai bahan aditif baru bagi karet alam (KA) terisi silika yang divulkanisasi menggunakan sistem vulkanisasi semi efisien. Pengisi silika yang digunakan adalah sebanyak 30 bagian per seratus bagian karet (bsk). Oleamida dihasilkan dari sintesa asam oleat dengan urea. Oleamida dimasukkan ke dalam kompon KA yang berpengisi silika dengan kadar 0,0 bsk; 2,0 bsk; 4,0 bsk; 6,0 bsk dan 8,0 bsk. Pengamatan dilakukan pada pengaruh oleamida terhadap karakteristik pematangan dari komposit KA terisi silika. Hasil diperoleh bahwa oleamida berfungsi sebagai bahan kuratif dan sebagai bahan pemlastis. Semakin besar kadar oleamida yang ditambahkan maka akan semakin pendek waktu skorj dan waktu pematangan optimum. Oleamida juga menurunkan tork minimum dengan penambahan hingga 8,0 bsk. Semakin besar kadar oleamida maka semakin menurun tork minimum. Oleamida juga menyebabkan peningkatan tork maksimum dan perbedaan tork pada komposit KA terisi silika pada penambahan 2,0 bsk. Penambahan oleamida sebanyak 2,0 bsk merupakan kadar optimum bagi komposit KA terisi silika.
\end{abstract}

Kata Kunci: karet alam, oleamida, silika, karakteristik pematangan, tork

\begin{abstract}
The purpose of this study was as a feasibility study of the utilization of oleamide as a new additive for natural rubber (NR) filled with silica using the semi-efficient vulcanization system. Silica fillers used as much as 30 parts per hundred parts rubber (phr). Oleamide was obtained from the synthesis of oleic acid with urea. Oleamide was inserted into the silica filled NR compounds with the varied composition of $0.0 \mathrm{phr} ; 2.0 \mathrm{phr}$; $4.0 \mathrm{phr} ; 6.0 \mathrm{phr}$, and $8.0 \mathrm{phr}$. The influence of oleamide on the curing characteristic of the silica filled NR compounds was observed. It was obtained that the oleamide functions as a curative and also a plasticizer. The greater the levels of oleamide added, the shorter the scorch time and optimum curing time were. Oleamide also decreased the minimum torque with addition up to $8.0 \mathrm{phr}$. The greater the levels of oleamide was, the lower the minimum torque was. Oleamide also increased the maximum torque and torque difference of the silica-filled NR composites at the addition of $2.0 \mathrm{phr}$. The $2.0 \mathrm{phr}$ was the optimum composition of the oleamide.
\end{abstract}

Keywords: natural rubber, oleamide, silica, curing characteristic, torque

\section{Pendahuluan}

Karet Alam (KA) diperoleh dari tanaman Hevea brasiliensisis adalah salah bahan baku komersil utama dalam pembuatan material karet, seperti penggunaan dalam industri pembuatan ban dan kesehatan. KA murni diperkirakan mengandung 94\% hidrokarbon karet dan 6\% komponen lainnya [1].

Vulkanisasi adalah suatu proses dimana molekul karet yang linier mengalami reaksi sambung silang sulfur (sulfur-crosslinking) sehingga menjadi molekul polimer yang membentuk rangkaian tiga dimensi. Reaksi ini merubah karet yang bersifat plastis (lembut) dan lemah menjadi karet yang elastis, keras dan kuat [2].

Salah satu pengisi populer yang digunakan dalam pembuatan kompon karet adalah silika. Silika memiliki sifat kimia sangat mudah menyerap air, mengandung gugus silanol dan sangat polar maka silika dapat mengakibatkan timbulnya aglomerasi 
yang dapat mengganggu proses pencampuran yang terjadi pada KA.

Hal ini merupakan masalah saat proses pendispersian silika pada KA. Untuk mengatasi masalah tersebut, maka perlu ditambahkan bahan aditif baru yaitu oleamida pada kompon KA terisi silika. Bahan ini berasal dari turunan minyak sawit yang bersifat polar dan non polar sehingga berpotensi sebagai bahan penyerasi (compatibilizer). Metode ini diharapkan dapat meningkatkan penyebaran silika dalam KA, sehingga menghasilkan sifat-sifat yang lebih baik bagi vulkanisat KA terisi silika.

\section{Teori}

KA, cis-1,4-polyisoprene, adalah bahan yang banyak digunakan di bagian elastomer karena menggabungkan regangan elastis yang sangat besar dengan kekuatan tarik yang tinggi dan ketahanan pertumbuhan retak yang luar biasa. Sifat-sifat luar biasa ini sebagian dikaitkan dengan fenomena kristalisasi yang diinduksi oleh regangan yang disebut dengan strain induced crystallization (SIC) yang terjadi pada KA. Kemampuan untuk mengkristal di bawah tekanan ini sering dijelaskan oleh keteraturan yang tinggi dari struktur makromolekul, yaitu persentase rantai yang berada dalam konfigurasi cis, yang sangat mendekati $100 \%$ dalam KA [3].

Produk KA umumnya memiliki kekuatan mekanik yang rendah. Oleh sebab itu, dalam pengolahannya perlu ditambahkan penguat seperti pengisi (filler) baik berupa pengisi anorganik maupun pengisi organik. Pengisi biasanya digunakan untuk meningkatkan sifat-sifat mekanikal dari vulkanisat KA seperti kekuatan tarik (tensile strength), ketahanan terhadap pengikisan dan pengoyakan atau untuk memurahkan harga suatu produk karet. Berdasarkan efek penguatan terhadap sifat-sifat karet (rubber properties), maka pengisi dapat dikelompokkan menjadi 3 yaitu penguat (reinforcing), semi penguat dan bukan penguat (non-reinforcing) [4].

Dalam industri karet, pengisi yang digunakan secara umum adalah carbon black, silika dan kalsium karbonat [5]. Silika merupakan senyawa amorphous yang mengandung silikon dan oksigen yang tersusun dalam struktur tetrahedral. Ukuran partikel silika bervariasi antara $1 \mathrm{~nm}$ sampai $30 \mathrm{~nm}$ dengan luas permukaan dari $20 \mathrm{~m}^{2} / \mathrm{g}$ sampai $300 \mathrm{~m}^{2} / \mathrm{g}$. Pada umumnya silika bersifat hidrofobik ataupun hidrofilik sesuai dengan struktur dan morfologinya. Selain itu silika juga bersifat non konduktor, memiliki ketahanan terhadap oksidasi dan degradasi termal yang baik [6].

Pemlastis adalah zat non-volatil dengan berat molekul rendah yang ditambahkan ke polimer untuk meningkatkan fleksibilitas dan kemampuan pemrosesan polimer itu sendiri. Bahkan jumlah kecil dari pemlastis secara signifikan mengurangi temperatur transisi kaca $\left(\mathrm{T}_{\mathrm{g}}\right)$ dari polimer. Hal ini dikarenakan reduksi dari gaya kohesi antara rantai polimer. Molekul pemlasits menembus ke dalam matriks polimer dan berperan sebagai pelumas antara rantai polimer yang mana menurunkan $\mathrm{T}_{\mathrm{g}}$ [7].

Oleamida merupakan salah satu dari senyawa amida yang mempunyai nitrogen trivalen yang terikat pada suatu gugus karbonil. Senyawa amida diberi nama dari asam karboksilat dengan mengubah imbuhan asam oat (atau - at) menjadi amida [8]. Oleamida di dalam pembuatan polimer nanokomposit digunakan sebagai agen penyambung antara zat silika dan polimer yang mengubah struktur partikel $\mathrm{SiO}_{2}$ karena mereka terikat pada gugus silanol pada permukaan nanosilika dengan ikatan hidrogen. Oleamida yang mengubah struktur partikel silika telah memberikan efisiensi yang baik dan dispersi yang stabil terhadap nanokomposit [9].

\section{Metodologi Penelitian}

Penelitian dilakukan di laboratorium kimia PT. Industri Karet Deli (IKD) Medan. KA dan bahanbahan kimia lainnya dikompon menggunakan alat two-roll mill milik PT. IKD.

\section{Bahan-bahan}

KA digunakan sebagai bahan dasar. Silika digunakan sebagai penguat pengisi. Bahan-bahan aditif lainnya yaitu asam stearat, sulfur (S), seng oksida (ZnO), antioksidan/N-Isopropil-N'phenil-p phenilena diamina (IPPD) dan akselerator/Mercaptobenzothiazolyl disulfida (MBTS). Oleamida diproduksi dari hasil sintesa urea dan asam oleat pada skala laboratorium. Kecuali oleamida, semua bahan disediakan oleh PT. Industri Karet Deli.

\section{Formulasi Kompon KA}

Vulkanisasi (semi efisien) digunakan untuk formulasi silika dengan KA dan oleamida yang dilakukan pada two roll mill (Model XK-160).

Tabel 1. Komposisi KA dan Silika dengan Penambahan Oleamida.

\begin{tabular}{|l|l|}
\hline \multicolumn{1}{|c|}{ Komponen } & \multicolumn{1}{c|}{ Jumlah (bsk) } \\
\hline $\mathrm{KA}$ & 100,0 \\
\hline $\mathrm{ZnO}$ & 5,0 \\
\hline $\mathrm{S}$ & 1,5 \\
\hline MBTS & 1,5 \\
\hline Silika & 30,0 \\
\hline IPPD & 2,0 \\
\hline Asam stearat & 2,0 \\
\hline Oleamida & 0,$0 ; 2,0 ; 4,0 ; 6,0 ; 8,0$ \\
\hline
\end{tabular}


Tabel 1 menunjukkan komposisi KA dan silika dengan penambahan oleamida. Tork maksimum $\left(\mathrm{M}_{\mathrm{H}}\right)$, tork minimum $\left(\mathrm{M}_{\mathrm{L}}\right)$ dan perubahan tork $\left(\mathrm{M}_{\mathrm{H}}-\mathrm{M}_{\mathrm{L}}\right)$ ditentukan berdasarkan SNI 3417 melalui penggunaan Rheometer (MDR 2000). Vulkanisasi dilakukan pada $150{ }^{\circ} \mathrm{C}$

\section{Pembuatan Kompon KA}

$\mathrm{KA}$, oleamida, silika dan bahan-bahan lainnya dicampur sampai keadaan homogen pada suhu konstan $\left( \pm 65^{\circ} \mathrm{C}-75^{\circ} \mathrm{C}\right)$ selama \pm 25 menit untuk satu siklus pencampuran pada two roll mill. Sampel senyawa KA yang berupa lembaran disimpan dengan kondisi $\pm 21^{\circ} \mathrm{C}-25^{\circ} \mathrm{C}$ selama \pm 24 jam di dalam freezer tertutup.

\section{Hasil dan Pembahasan}

\section{Karakterisasi FTIR Oleamida}

Hasil pengujian Fourier Transform InfraRed (FTIR) untuk oleamida dapat dilihat pada Gambar 1.

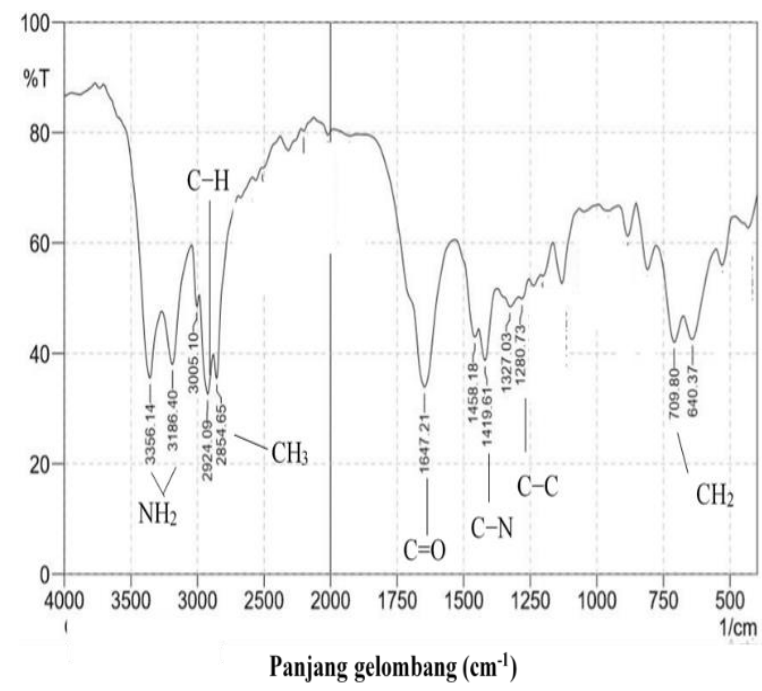

\section{Gambar 1. Spektrum Infra Merah Oleamida}

Dari Gambar 1 dapat dilihat spektrum infra merah yang menunjukkan panjang gelombang dari gugus-gugus fungsional yang menyusun molekul oleamida. Dapat dilihat, panjang gelombang 2924,09 $\mathrm{cm}^{-1}$ menunjukkan adanya gugus $\mathrm{C}-\mathrm{H}$. Panjang gelombang 2854,65 $\mathrm{cm}^{-1}$ menunjukkan adanya gugus metil $\left(\mathrm{CH}_{3}\right)$ yang melekat pada atom karbon. Panjang gelombang $709,80 \mathrm{~cm}^{-1}$ menunjukkan adanya gugus metilen $\left(\mathrm{CH}_{2}\right)$ yang melekat pada atom karbon. Panjang gelombang yang menunjukkan adanya gugus $\mathrm{C}=\mathrm{O}, \mathrm{C}-\mathrm{C}, \mathrm{C}-\mathrm{N}, \mathrm{N}-\mathrm{H}$, secara berurutan adalah $1647,21 \mathrm{~cm}^{-1}, 1280,73 \mathrm{~cm}^{-1}, 1419,61 \mathrm{~cm}^{-1}, 3184,40$ $\mathrm{cm}^{-1}$ dan $3356,14 \mathrm{~cm}^{-1}$.

Berdasarkan spektrum tersebut dengan jelas menunjukkan adanya panjang gelombang dari gugusgugus fungsional molekul oleamida, dimana senyawa ini merupakan suatu senyawa yang mempunyai nitrogen trivalen (bervalensi tiga) yang terikat pada suatu gugus karbonil serta memiliki satu gugus karbonil berikatan rangkap, sehingga dapat dipastikan bahan tersebut adalah oleamida dengan rumus molekul $\mathrm{CH}_{3}\left(\mathrm{CH}_{2}\right)_{7} \mathrm{CH}=\mathrm{CH}\left(\mathrm{CH}_{2}\right)_{7} \mathrm{CONH}_{2}$.

\section{Waktu Skorj dan Waktu Pematangan Optimum}

Pengaruh penambahan oleamida terhadap waktu skorj dan waktu pematangan optimum dari kompon KA terisi silika dapat dilihat pada Gambar 2.

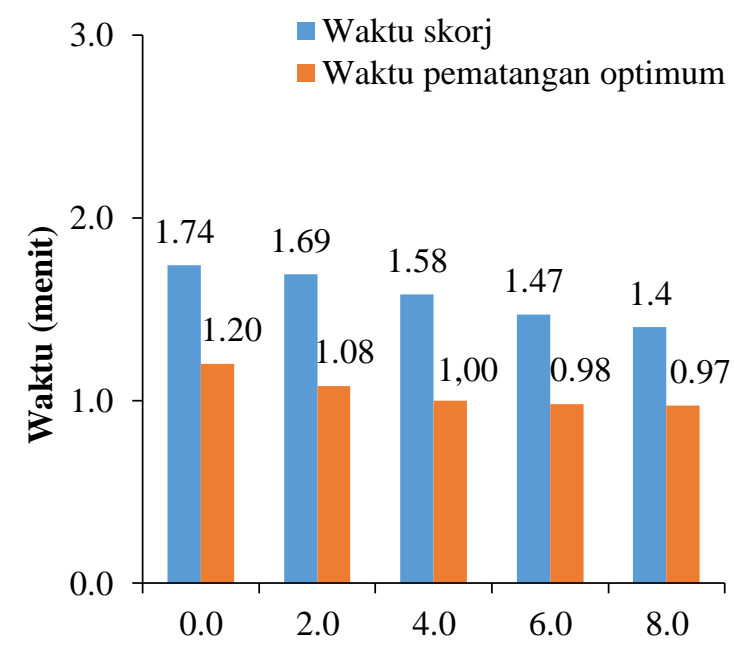

Kadar Oleamida (bsk)

Gambar 2. Pengaruh Kadar Oleamida Terhadap Waktu Skorj dan Waktu Pematangan Optimum Kompon KA Terisi Silika

Dari Gambar 2 diatas dapat dilihat bahwa penambahan oleamida sebanyak 2,0 bsk menyebabkan terjadinya penurunan waktu skorj $\left(\mathrm{t}_{\mathrm{s} 2}\right)$ dan penurunan waktu pematangan ( $\left.\mathrm{t}_{90}\right)$ dari kompon kontrol $(0,0$ bsk $)$. Waktu skorj $\left(\mathrm{t}_{\mathrm{s} 2}\right)$ dan waktu pematangan $\left(t_{90}\right)$ terus menurun dengan penambahan lebih lanjut hingga 8,0 bsk.

Hal ini dikarenakan gugus amina yang terdapat dalam oleamida merupakan bahan pencepat yang bersifat polar yang dapat menurunkan waktu pematangan dan waktu skorj karena gugus amina berinteraksi dengan gugus silanol pada silika sehingga gugus polar tersebut akan mencegah permukaan silika untuk menyerap bahan pencepat yang dapat memperlambat laju pematangan dan meningkatkan derajat keasaman $(\mathrm{pH})$ dari kompon KA sehingga menyebabkan percepatan waktu pematangan kompon karet tersebut [10].

Penelitian sebelumnya telah melaporkan bahwa bahan aditif seperti oleamida memungkinkan terjadinya reaksi vulkanisasi yang lebih cepat yaitu menurunkan waktu skorj dan waktu pematangan optimum bila dibandingkan dengan karet yang tidak ditambahkan oleamida [11]

Penambahan kadar oleamida berhubungan dengan penambahan kadar amida pada kompon KA terisi silika yang menunjukkan semakin singkat waktu 
pematangan dan waktu skorj yang diperlukan untuk proses vulkanisasi kompon KA terisi silika.

\section{Nilai Tork Minimum dan Tork Maksimum}

Pengaruh penambahan oleamida terhadap nilai tork minimum dan tork maksimum dari kompon KA terisi silika dapat dilihat pada Gambar 3.

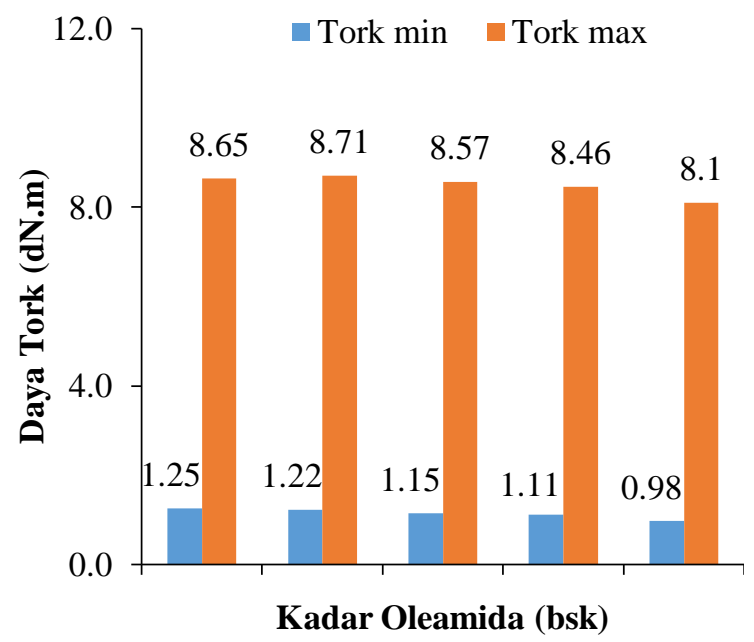

Gambar 3. Pengaruh Kadar Oleamida terhadap Daya Tork Kompon KA Terisi Silika

Dari Gambar 3, dapat dilihat bahwa penambahan oleamida sebanyak 2,0 bsk ke dalam kompon KA menyebabkan penurunan nilai $\mathrm{M}_{\mathrm{L}}$ (tork minimum) hingga penambahan sebanyak 8,0 bsk dibandingkan dengan kompon kontrol (0,0 bsk).

Tork minimum $\left(\mathrm{M}_{\mathrm{L}}\right)$ mengindikasikan interaksi pengisi dengan pengisi dan viskositas kompon karet. Semakin kecil nilai $\mathrm{M}_{\mathrm{L}}$ maka semakin rendah viskositas kompon karet dan menghasilkan interaksi yang kuat antara oleamida dengan pengisi silika dan mengurangi interaksi pengisi dan pengisi yang akan membentuk aglomerasi sehingga derajat dispersi pengisi silika dapat ditingkatkan [4]. Penambahan oleamida ke dalam kompon KA terisi silika menurunkan viskositas kompon tersebut. Hal ini disebabkan oleh pelunakan atau efek pelumas dari oleamida. Penambahan oleamida yang lebih banyak menyebabkan penurunan viskositas yang lebih lanjut.

Oleamida memberikan efek yang menguntungkan terhadap interkalasi yang merupakan proses pengeluaran mineral dari karet. Sebagaimana diketahui bahwa oleamida memasuki celah antar lapisan dari struktur silika yang berlapis selama proses pencampuran dan vulkanisasi dari kompon karet dan memungkinkan interkalasi terjadi di dalam rantai karet tersebut [12].

Dari Gambar 3 juga dapat dilihat bahwa tork maksimum $\left(\mathrm{M}_{\mathrm{H}}\right)$ meningkat dengan ditambahkannya oleamida sebanyak 2,0 bsk ke dalam kompon KA berpengisi silika. Tork maksimum mengindikasikan modulus stok pada karet. Tork maksimum mengalami penurunan pada penambahan yang lebih besar dari 2,0 bsk.

Peningkatan nilai $\mathrm{M}_{\mathrm{H}}$ disebabkan oleh keberadaan oleamida yang membantu proses interkalasi. Interkalasi adalah proses masuknya suatu senyawa ke dalam kompon karet dengan cara menyisipkannya ke dalam molekul karet sehingga membentuk struktur bahan yang berlapis. Pada proses ini pengisi silika lebih mudah didispersikan ke dalam kompon karet sehingga interaksi kompon karet dengan silika meningkat [13].

Pada penambahan oleamida yang lebih besar dari 2,0 bsk menyebabkan nilai $\mathrm{M}_{\mathrm{H}}$ menurun. Nilai $\mathrm{M}_{\mathrm{H}}$ merupakan ukuran kekakuan kompon KA. Semakin tinggi nilai $\mathrm{M}_{\mathrm{H}}$ maka semakin kaku vulkanisat karet. Penambahan oleamida yang berlebih ke dalam kompon karet terisi silika menurunkan sifat kekakuan. Hal ini disebabkan oleh oleamida yang berfungsi sebagai pemlastis. Oleamida mengisi ruangruang di dalam fasa karet yang menyebabkan kompon menjadi lentur sehingga mengurangi daya yang diperlukan untuk menggerakkan kompon tersebut di dalam rheometer.

\section{Perbedaan Nilai Tork $(\Delta \mathrm{T})$}

Pengaruh penambahan oleamida terhadap perbedaan nilai tork $(\Delta \mathrm{T})$ dari kompon KA terisi silika dapat dilihat pada Gambar 4.

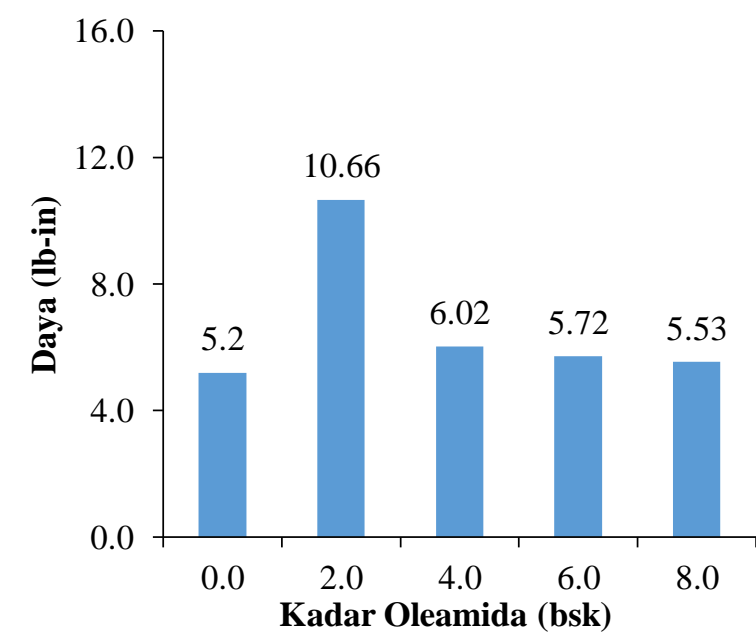

Gambar 4. Pengaruh Kadar Oleamida terhadap Daya Perbedaan Tork $(\Delta T)$ Kompon KA Terisi Silika

Dari Gambar 4, terlihat bahwa penambahan oleamida hingga 2,0 bsk menyebabkan kenaikan nilai perbedaan tork $(\Delta \mathrm{T})$ dari kompon KA terisi silika. Penambahan kadar diatas 2,0 bsk menyebabkan nilai $\Delta \mathrm{T}$ mulai menurun. Perbedaan tork mengindikasikan total kerapatan sambung silang suatu kompon karet. Jika nilai $\Delta \mathrm{T}$ meningkat maka kerapatan sambung silang juga meningkat, demikian sebaliknya [14].

Oleamida dapat bertindak sebagai bahan yang membantu proses atau reaksi sambung silang 
(curative agent), yaitu dapat membentuk sambung silang tambahan, baik sambung silang secara kimia maupun sambung silang fisikal antara silika dengan kompon karet. Penambahan sambung silang ini menyebabkan peningkatan kerapatan sambung silang vulkanisat karet. Sedangkan total kerapatan sambung silang secara relatif dapat diukur dari nilai perbedaan tork (tork maksimum - tork minimum) [15].

Pada penambahan yang lebih dari 2,0 bsk, vulkanisat mengalami penurunan kerapatan sambung silang karena kadar bahan tersebut bertindak sebagai pelarut yang membuat bahan kuratif di dalam kompon karet melarut ke dalam bahan tersebut, sehingga menyebabkan penurunan kerapatan sambung silang bagi vulkanisat karet tersebut. Penurunan nilai $\Delta T$ disebabkan oleh kelebihan oleamida menyebabkan penurunan interkalasi silika ke dalam molekul KA.

\section{Kesimpulan}

Oleamida berfungsi sebagai bahan kuratif bagi kompon Karet Alam terisi silika, karena memendekkan waktu skorj (scorch delay) dan memendekkan waktu pematangan optimum hingga penambahan sebanyak 8,0 bsk. Oleamida menurunkan tork minimum hingga penambahan sebanyak 8,0 bsk, hal ini dikarenakan oleamida berfungsi sebagai bahan pemlastis yang berperan untuk menurunkan viskositas kompon. Selanjutnya oleamida meningkatkan tork maksimum dan perbedaan tork hingga penambahan sebanyak 2,0 bsk, hal ini dikarenakan oleamida mampu membantu proses interkalasi yang juga menyebabkan kompon karet menjadi semakin kaku.

\section{Ucapan Terima Kasih}

Penulis mengucapkan terima kasih kepada PT. Industri Karet Deli, Medan yang telah memberikan fasilitas penelitian sehingga penelitian ini terlaksana.

\section{Daftar Pustaka}

[1] Y. Wei, H. Zhang, L. Wu, L. Jin, and S. Liao, "A review on characterization of molecular structure of natural rubber," MOJ Polym. Sci., vol. 1, no. 6, pp. 197-199, 2017.

[2] M. Akiba and A. S. Hashim, "Vulcanization and crosslinking in elastomers," Prog. Polym. Sci., vol. 22, no. 3, pp. 475-521, 1997.

[3] B. Huneau, "Strain-induced crystallization of natural rubber: A review of X-ray diffraction investigations," Rubber Chem. Technol., vol. 84, p. 425-452, 2011.

[4] R. W. Sianturi and I. Surya, "Pengaruh penambahan lauril alkohol terhadap sifat-sifat uji tarik komposit karet alam terisi silika," J. Tek. Kim. USU, vol. 7, no. 1, pp. 48-53, 2018.

[5] A. I. Al-Mosawi, M. M. Ali and J. H. Mohmmed, "Experimental approach to mechanical properties of natural rubber mixing with calcium carbonate powder," Int.
J. Phys. Sci., vol. 7, no. 49, pp. 6280-6282, 2012.

[6] K. Rajkumar, P. Ranjan, P. Thavamani, P. Jeyanthi, and P. Pazhanisamy, "Dispersion studies of nanosilica in nbr based polymer nanocomposite," Rasayan J. Chem., vol. 6, no. 2, pp. 122-133, 2013.

[7] P. Raju, V. Nandanan, and S. K. N. Kutty, “A study on the use of linseed oil as plasticiser in natural rubber compounds," J. Rbber Res., vol. 11, no. 3, pp. 147-162, 2008.

[8] L. M. Tirtayasa, "Pra rancangan pabrik pembuatan oleamida dari asam oleat dan urea dengan kapasitas produksi 10.000 ton/tahun," Skripsi, Universiats Sumatera Utara, Medan, 2012.

[9] M. Pishvaei and F. F. Tabrizi, "Synthesis of high solid content polyacrylate/nanosilica latexes via miniemulsion polymerization," Iran. Polym. J., vol. 19, no. 9, pp. 1-12, 2010.

[10] S. Prasertsri and N. Rattanasom, "Mechanical and damping properties of silica/natural rubber composites prepared from latex system," Polym. Test., vol. 30, no. 5, pp. 515526, 2011.

[11] M. H. Harandi, F. Alimoradi, G. Rowshan, M. Faghihi, M. Keivani, and M. Abadyan, "Morphological and mechanical properties of styrene butadiene rubber/nano copper nanocomposites," Results Phys., vol. 7, pp. 338-344, 2017.

[12] A. Das, K. W. Stöckelhuber, R. Jurk, D. Jehnichen, and G. Heinrich, "A general approach to rubber-montmorillonite nanocomposites: Intercalation of stearic acid," Appl. Clay Sci., vol. 51, no. 1-2, pp. 117-125, 2011.

[13] P. L. Teh, Z. A. M. Ishak, A. S. Hashim, J. Karger-Kocsis, and U. S. Ishiaku, "Effects of epoxidized natural rubber as a compatibilizer in melt compounded natural rubberorganoclay nanocomposites," Eur. Polym. J., vol. 40, no. 11, pp. 2513-2521, 2004.

[14] H. L. Tampubolon, D. S. Hutapea, and I. Surya, "Pengaruh penambahan alkanolamida terhadap karakteristik pematangan dan kekerasan vulkanisat karet alam berpengisi silika," J. Tek. Kim. USU, vol. 1, no. 1, pp. 710, 2012.

[15] Y. Widyanata, I. M. S. Sitorus, and I. Surya, "Pengaruh penambahan alkanolamida terhadap sifat-sifat uji tarik vulkanisat karet alam berpengisi kaolin," J. Tek. Kim. USU, vol. 2, no. 4, pp. 1-5, 2013. 